\title{
ARTICLE OPEN Formation and composition of the UTLS aerosol
}

\author{
Bengt G. Martinsson (D) ${ }^{1 *}$, Johan Friberg (D) ${ }^{1}$, Oscar S. Sandvik (D) ${ }^{1}$, Markus Hermann ${ }^{2}$, Peter F. J. van Velthoven ${ }^{3}$ and Andreas Zahn ${ }^{4}$
}

Stratospheric aerosol has long been seen as a pure mixture of sulfuric acid and water. Recent measurements, however, found a considerable carbonaceous fraction extending at least $8 \mathrm{~km}$ into the stratosphere. This fraction affects the aerosol optical depth (AOD) and the radiative properties, and hence the radiative forcing and climate impact of the stratospheric aerosol. Here we present an investigation based on a decade (2005-2014) of airborne aerosol sampling at 9-12 km altitude in the tropics and the northern hemisphere $(\mathrm{NH})$ aboard the IAGOS-CARIBIC passenger aircraft. We find that the chemical composition of tropospheric aerosol in the tropics differs markedly from that at NH midlatitudes, and, that the carbonaceous stratospheric aerosol is oxygenpoor compared to the tropospheric aerosol. Furthermore, the carbonaceous and sulfurous components of the aerosol in the lowermost stratosphere (LMS) show strong increases in concentration connected with springtime subsidence from overlying stratospheric layers. The LMS concentrations significantly exceed those in the troposphere, thus clearly indicating a stratospheric production of not only the well-established sulfurous aerosol, but also a considerable but less understood carbonaceous component.

npj Climate and Atmospheric Science (2019)2:40; https://doi.org/10.1038/s41612-019-0097-1

\section{INTRODUCTION}

Discrepancies between measured and modeled climate evolution occurring in recent years ${ }^{1,2}$ have largely been attributed to limited understanding of natural climate variations, mainly the interdecadal Pacific oscillation, ${ }^{3}$ solar forcing ${ }^{4}$ and volcanic aerosol in the stratosphere. ${ }^{5}$ An improved understanding of the stratospheric aerosol load and the associated radiative forcing ${ }^{6-8}$ is thus of great importance for climate predictions.

In the Brewer-Dobson circulation (Fig. 1) air from the tropical upper troposphere (UT) enters the tropical stratosphere. After transport for months to years in its lower or upper stratospheric branches, the air is transported down to the lowermost stratosphere (LMS), and, eventually back to the troposphere, at mid and high latitudes. This circulation induces a seasonal variation of concentrations of species in the LMS, where species formed in the stratosphere, like ozone and particulate sulfur, display a distinct spring maximum. ${ }^{9,10}$ As a result, the stratospheric influence on the LMS varies over the year with strong influence in the winter/spring and weak influence during summer/fall. ${ }^{11,12}$ The Brewer-Dobson circulation is complemented by a tropical/subtropical intrusion of tropospheric air (green arrow in Fig. 1) in the summer and early fall $^{13,14}$ forming the so-called Asian tropopause aerosol layer (ATAL).$^{15}$ The latter transport path is estimated to contribute $15 \%$ of the northern hemisphere $(\mathrm{NH})$ stratospheric aerosol surface area column during periods when the influence from volcanism is small. ${ }^{16}$ In approximately the same period as studied here, several volcanic eruptions increased the global stratospheric aerosol optical depth (AOD) by on average $40 \% .^{17}$

The stratospheric aerosol contains a large fraction of sulfuric acid and water, a carbonaceous fraction and some minor components of extraterrestrial or tropospheric origin. ${ }^{18-21}$ The carbonaceous aerosol is mainly organic ${ }^{10}$ with a small fraction of black carbon. ${ }^{22,23}$ Wildfires supply significant amounts of organic material to the stratosphere, ${ }^{24}$ together with other sources such as biogenic and anthropogenic emissions. Sulfurous aerosol is formed in the stratosphere mainly from the gaseous precursors carbonyl sulfide (OCS) and sulfur dioxide $\left(\mathrm{SO}_{2}\right) \cdot{ }^{25,26}$ Studies that deal with formation of organic aerosol in the stratosphere are few, although some infer stratospheric implications from laboratory studies. ${ }^{27-29}$ Most of the observations of organic aerosol instead have been obtained in the troposphere or in laboratory experiments. $^{30,31}$ Primary organic aerosol (POA) and volatile organic compounds (VOC) are oxidized in the atmosphere. The resulting reduction in vapor pressure of the latter causes formation of secondary organic aerosol (SOA). The oxygen-tocarbon ratio $(\mathrm{O} / \mathrm{C})$ is often used as a measure of the degree of oxidation of organic aerosol. Several studies of organic aerosol in the planetary boundary layer yield molecular O/C ratios in the range $0.2-0.8 .^{32,33}$ Molecules with even higher ratios have been produced in the laboratory. ${ }^{34}$ They can play an important role in early stages of new particle formation. ${ }^{35}$ Oligomerization constitutes an additional path of lowering the vapor pressure to form SOA. Photochemical aging of the organic aerosol induces fragmentation, which could be a significant sink of organic aerosol. $^{36,37}$ Large differences in terms of chemical composition, residence times and actinic flux between the lower troposphere and the UTLS preclude a direct application of these results.

This study is based on ten years of aerosol samples taken during monthly sets of usually four intercontinental flights of the IAGOSCARIBIC observatory. ${ }^{38}$ During post-flight analysis the aerosol elemental composition is obtained. Periods strongly affected by volcanic eruptions were excluded in this study, see the methods section for further details. Here we investigate the composition of the aerosol in the NH midlatitudes LMS and UT and the middle troposphere (MT) of the tropics, focusing on the formation of sulfurous and carbonaceous aerosol in the stratosphere.

\section{RESULTS}

Tropical and $\mathrm{NH}$ aerosol concentrations at 9-12 km altitude The sulfurous and carbonaceous components of the aerosol at 9-12 km altitude are investigated based on concentrations of the

'Division of Nuclear Physics, Lund University, Lund, Sweden. ${ }^{2}$ Leibniz Institute for Tropospheric Research, Leipzig, Germany. ${ }^{3}$ Royal Netherlands Meteorological Institute (KNMI), De Bilt, Netherlands. ${ }^{4}$ Institute of Meteorology and Climate Research, Karlsruhe Institute of Technology, Karlsruhe, Germany. ${ }^{*}$ email: bengt.martinsson@nuclear.lu.se 


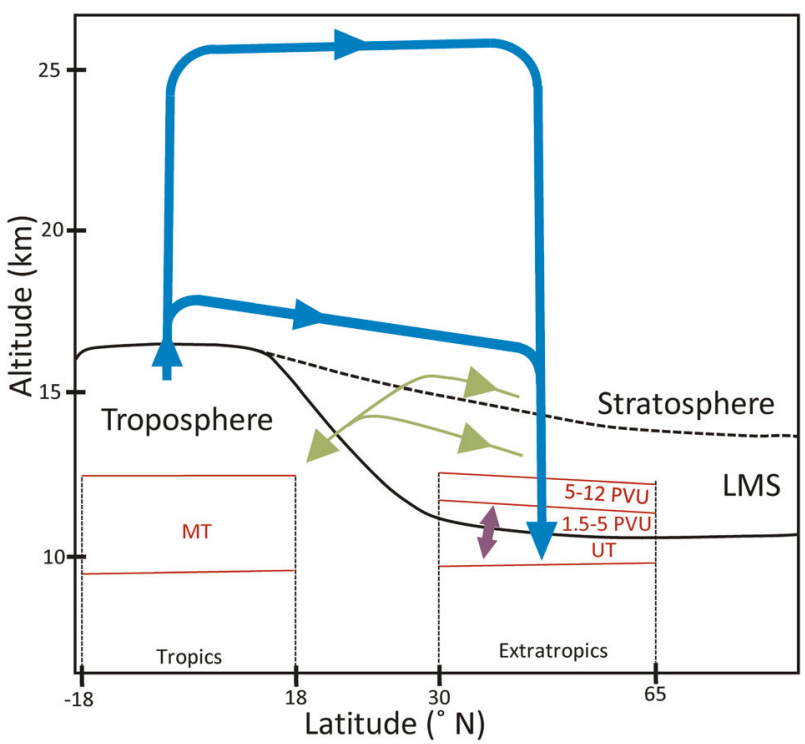

Fig. 1 Schematic sketch of the vertical circulation of the upper troposphere and lower stratosphere (UTLS). The tropopause separating the troposphere and the stratosphere is indicated by a solid black line, and the top of the lowermost stratosphere (LMS), at the potential temperature surface of $380 \mathrm{~K}$, by a dashed black line. The blue lines illustrate the net troposphere-stratosphere circulation, where tropospheric air enters the stratosphere in the tropics, is transported to higher latitudes in the low and high branches of the Brewer-Dobson circulations, where, in the latter, the so called Junge aerosol layer is formed. Air is transported back to the troposphere via the LMS at mid and high latitudes. The green lines show the net summer intrusion of tropospheric air due to a weakened blocking at the subtropical jet, enhanced by the Asian summer monsoon, where the Asian tropopause aerosol layer (ATAL) is formed. The purple arrow indicates the bi-directional exchange across the tropopause forming the extratropical transition layer (ExTL). The red features show the sampling locations of this study in the tropical middle troposphere (MT), the extratropical upper troposphere (UT), and the LMS in the potential vorticity ranges 1.5-5 PVU and 5-12 PVU

elements sulfur, carbon and oxygen. The former two elements represent the two main aerosol components, sulfurous and carbonaceous aerosol, whereas oxygen usually is the largest constituent by mass and part of both main components. Figure $2 a$ shows extratropical UT aerosol elemental concentrations. For some months the UT data are left out, because of insufficient statistical significance due to small numbers of samples. For sulfur and oxygen, we find a clear spring/early summer maximum in concentration associated with the strong stratospheric influence on the extratropical UT sulfurous aerosol concentration. ${ }^{11}$ The carbon concentration, which is dominated by organic aerosol constituents, peaks in the summer (Fig. 2a). In the tropical MT (Fig. 2b) carbon rather than oxygen is the most abundant element, compare the UTLS regions presented in Fig. 2. Further, particulate sulfur is clearly lower than in the extratropical UT, consistent with a very small stratospheric influence in the tropics. The tropospheric concentrations will be discussed further.

The LMS concentrations are studied in two layers (Fig. 1). The lowest layer (1.5-5 PVU), Fig. 2c, constitutes approximately the extratropical transition layer (ExTL), where the concentrations are affected by fast air exchange across the local tropopause. ${ }^{39}$ The upper layer (5-12 PVU), Fig. 2d, is much less affected by local cross-tropopause exchange. The concentrations of all three elements are higher in the LMS than in the extratropical UT, compare Fig. 2a with Fig. 2c, d. The highest concentrations are found in the upper LMS layer, as the lower layer is more affected by tropospheric air. All three elements display a clear seasonal

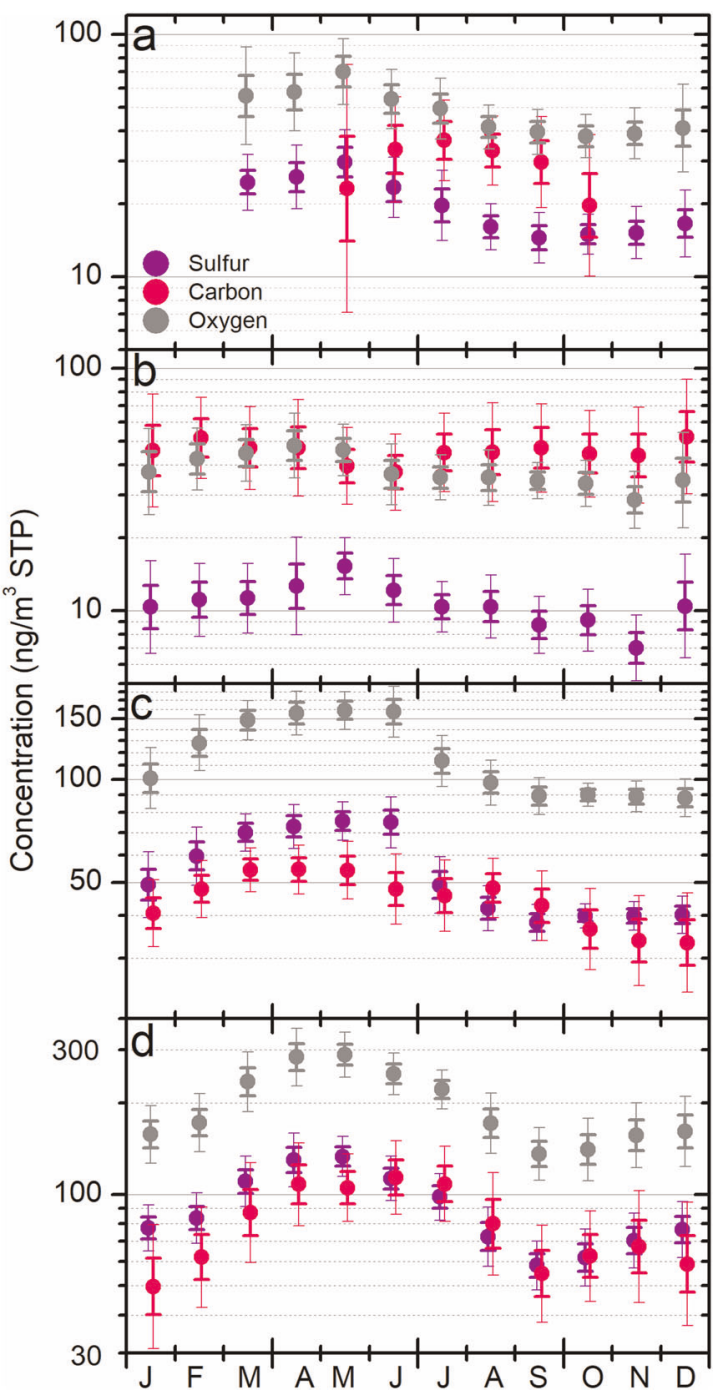

Fig. 2 Seasonal variation in aerosol elemental concentrations. Particulate sulfur (S), carbon (C) and oxygen (O) concentrations (3month running average, center month given at the $x$-axis) at 9-12 km altitude are shown for: a the upper troposphere in latitude range $30-65^{\circ} \mathrm{N}, \mathbf{b}$ the middle troposphere in the latitude range $18^{\circ}$ $\mathrm{S}-18^{\circ} \mathrm{N}$, c the lowermost stratosphere (LMS) in the potential vorticity (PV) 1.5-5 PVU and latitudes $30-65^{\circ} \mathrm{N}$, and $\mathbf{d}$ the LMS in the $\mathrm{PV}$ range $5-12 \mathrm{PVU}$ and latitudes $30-65^{\circ} \mathrm{N}$. Thick and thin error bars show the geometrical standard error and the 95\% confidence interval of the geometrical mean, respectively

variation in both LMS layers with maximum concentration in the late spring (Fig. 2c, d), carbon differing by prolonged high concentrations over the summer. Sulfur and oxygen, and, to a lesser extent carbon, are at minimum concentration in fall in the upper LMS layer, whereas the lower layer has a broader fall minimum. The winter/spring rise in concentrations are caused by extratropical stratospheric downward transport in the BrowerDobson circulation, which at the top of the LMS ( $380 \mathrm{~K}$ isentrope) maximizes in the winter. ${ }^{40}$ The summer decrease in the sulfurous aerosol concentration in the upper layer is connected with a weakened downwards transport in the Brewer-Dobson circulation and a seasonally varying exchange around the subtropical jet with maximum in summer and early fall, transporting tropospheric air into this layer. ${ }^{41}$ The delayed decline in the carbon concentration is likely caused by summertime influence from wildfires, ${ }^{42}$ increasing the concentration of carbonaceous aerosol in the LMS, $^{23}$ and the formation of the ATAL. ${ }^{11,16,43}$ The concentrations in 


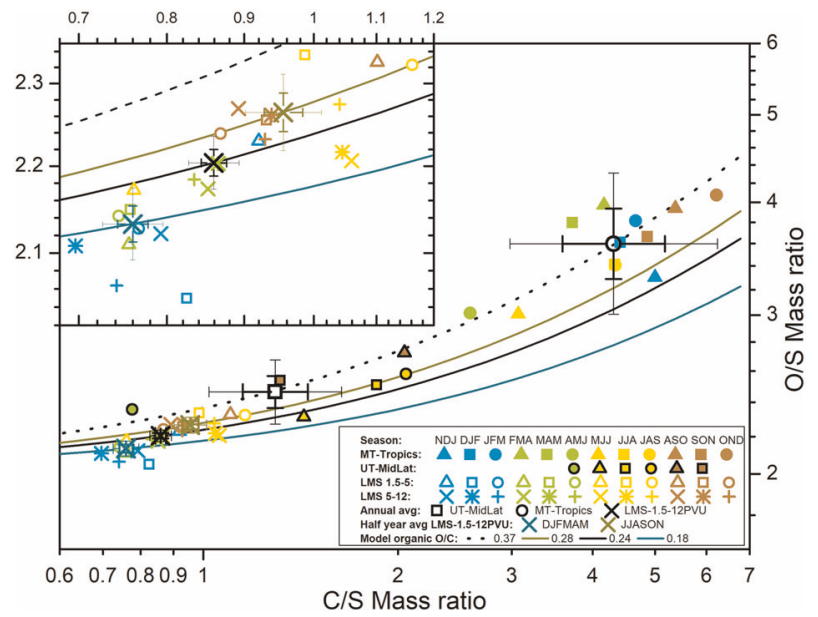

Fig. 3 Aerosol composition. The mass concentration ratios of the aerosol particle components oxygen to sulfur (O/S) Vs. carbon to sulfur $(C / S)$. The inset magnifies the region with data from the lowermost stratosphere (LMS). Three-month running geometrical mean of the elemental ratios are used for measurements from the LMS in two potential vorticity intervals, the midlatitude upper troposphere (UT), the tropical middle troposphere (MT), annual averages of the three atmospheric parts, and half-year averages of the LMS. The four lines ("model") show the positions of organic O/C ratios, assuming sulfur in the form of sulfate (i.e., four oxygen to each sulfur atom). Thick and thin error bars show the geometrical standard error and the $95 \%$ confidence interval of the geometrical mean, respectively. The molar $\mathrm{O} / \mathrm{C}$ ratio is 0.75 times the $\mathrm{O} / \mathrm{C}$ ratio by mass

the lower LMS layer are affected both by transport of lower concentrations from the upper layer and by a downwards movement of the tropopause during fall, ${ }^{40}$ which incorporates tropospheric air into the LMS.

\section{Aerosol composition along the Brewer-Dobson circulation}

After the investigation of the aerosol elemental concentrations in the four regions (Fig. 2), we now turn the attention to the aerosol composition. To this end, two ratios of aerosol elemental concentrations are formed: carbon to sulfur (C/S), and oxygen to sulfur $(\mathrm{O} / \mathrm{S})$. These ratios show strong dependence on sampling location, implying vast differences in chemical composition, see Fig. 3. The data are presented as three-month moving geometrical means together with annual and, in one case, semiannual means. The tropical MT aerosol shows the highest $\mathrm{C} / \mathrm{S}$ and O/S ratios, each mean exceeding those of all other regions. With annual average mass ratios $\mathrm{C} / \mathrm{S}$ of 4.3 and $\mathrm{O} / \mathrm{S}$ of 3.6 (the $\mathrm{O} / \mathrm{S}$ mass ratio of sulfate is 1.99), the tropical region, with strong biogenic ${ }^{44}$ and wildfire ${ }^{45}$ emissions, is the only part of the atmosphere investigated here that is not dominated by sulfurous aerosol. The lowest C/S and O/S appear in the LMS with mean $\mathrm{C} / \mathrm{S}$ and $\mathrm{O} / \mathrm{S}$ mass ratios of 0.9 and 2.2, thus expressing the importance of sulfurous aerosol in the stratosphere. The extratropical UT has a composition in between those of the tropical MT and LMS compositions, but is more oriented towards the latter. This is in line with the previous finding of a strong influence of stratospheric aerosol on the extratropical UT aerosol. ${ }^{11,46}$

Sulfate is the dominating form of the sulfurous aerosol in the atmosphere. $^{47,48}$ To further evaluate Fig. 3 we make the assumption that all the particulate sulfur is in the form of sulfate by assigning four oxygen atoms to each sulfur atom. The residual oxygen $\left(\mathrm{O}_{\mathrm{r}}\right)$ is assigned to the carbonaceous fraction. In Fig. 3 lines with various ratios of residual oxygen to carbon are displayed. The tropospheric measurements are found around a line with mass ratio $\mathrm{O}_{\mathrm{r}} / \mathrm{C}=0.37$, whereas the stratospheric ones hold a clearly lower residual oxygen-to-carbon ratio with the lowest ratio in winter/spring $\left(\mathrm{O}_{\mathrm{r}} / \mathrm{C}\right.$ mass ratio of 0.18$)$ when the influence on the LMS from the overlying stratosphere is strongest. Realistic alteration of the sulfurous aerosol composition has a small influence on the inferred organic composition. A change in the tropical composition, which is the most likely location due to the strong sulfate production in the stratosphere, to $95 \%$ sulfate and $5 \%$ MSA (methanesulfonic acid) would cause a minimal change in the residual oxygen-to-carbon mass ratio $\left(\mathrm{O}_{\mathrm{r}} / \mathrm{C}\right)$, from 0.37 to 0.375. The LMS samples from the periods most affected by volcanism (not shown here) tend to be oriented similar to the winter/spring LMS data in the $\mathrm{C} / \mathrm{S}-\mathrm{O} / \mathrm{S}$ space (Fig. 3). In the previous section we found that the proportions of the sulfurous and carbonaceous fractions of the aerosol varies greatly with location. Here we find that the average chemical composition of the main chemical compounds in the stratosphere is different from that of the extratropical UT and tropical MT, the former being shifted to an oxygen-poor carbonaceous aerosol.

\section{DISCUSSION}

Finally, we compare concentrations in several regions along the troposphere/stratosphere vertical circulation illustrated in Fig. 1. At latitudes of stratosphere-to-troposphere outflow, we have data from two LMS layers and the UT. To study the inflow to the stratosphere the best option available is to use data from the tropical MT to represent the tropical aerosol entering the stratosphere. In Fig. 4 the concentrations in these four regions along the troposphere/stratosphere vertical circulation is shown. For the extratropical layers the months when the stratospheric influence on the LMS aerosol is at maximum (spring; AMJ) and minimum (fall; SON) are shown, and for the tropical MT the annual mean is used. Ozone is a good example of a species with strong production in the stratosphere (Fig. 4a). Particulate sulfur shows a similar pattern, with concentrations in the tropics more than an order of magnitude lower than those in the upper layer of the LMS (Fig. 4b), consistent with the well-established production of sulfurous aerosol in the stratosphere. ${ }^{25,26}$ This production affects the oxygen concentrations too (Fig. 4d). Furthermore, Fig. 4c shows that the carbon concentrations in the LMS are clearly higher than in the tropical MT. This indicates production of carbonaceous aerosol in the stratosphere, or direct injection of carbonaceous aerosol into the stratosphere as observed from wildfires. ${ }^{24,42,49}$ Laboratory studies show that photo degradation could affect SOA budgets by a loss rate of at least $1 \%$ per $24 \mathrm{~h}$ with considerably higher rates in the stratosphere leading to the prediction that photo degradation efficiently depletes organic particles from the stratosphere. ${ }^{29}$ Modeling indicates a tropospheric photolytic loss rate of $40-60 \%$ of SOA mass over 10 days for most species. ${ }^{50}$ Due to the low probability of cloud formation the aerosol transport times in the stratosphere are much longer than in the troposphere. Aerosol from wildfires is dominated by organic compounds by mass. ${ }^{51} \mathrm{~A}$ recent study on the evolution in the stratosphere of the smoke from 2017 western Canadian wildfires found a reduction of the smoke life time of $40 \%$ attributed to photochemical loss of organic carbon. ${ }^{52}$ Due to a delayed arrival of the smoke to altitude range investigasted, ${ }^{52}$ that study may not fully include approximately the first month of smoke evolution. To further illuminate this process in the stratosphere we use two graphs from published papers: the aerosol from the August 2017 western Canadian wildfires (Peterson et al., their Fig. 4b), ${ }^{42}$ and the upper volcanic cloud from the Kasatochi eruption in August 2008 (Friberg et al., their Fig. 8b, 380-470 K). ${ }^{17}$ These aerosol clouds reached approximately the same altitude in the same season, when the extratropical downward transport in the Brewer-Dobson circulation is weak. ${ }^{40}$ The wildfire shows decline already within the first two weeks. The volcanic aerosol, dominated by sulfate, ${ }^{20}$ was still increasing the first 3 months due to formation of sulfate from sulfur dioxide and size distribution evolution, and shows 


\section{4}

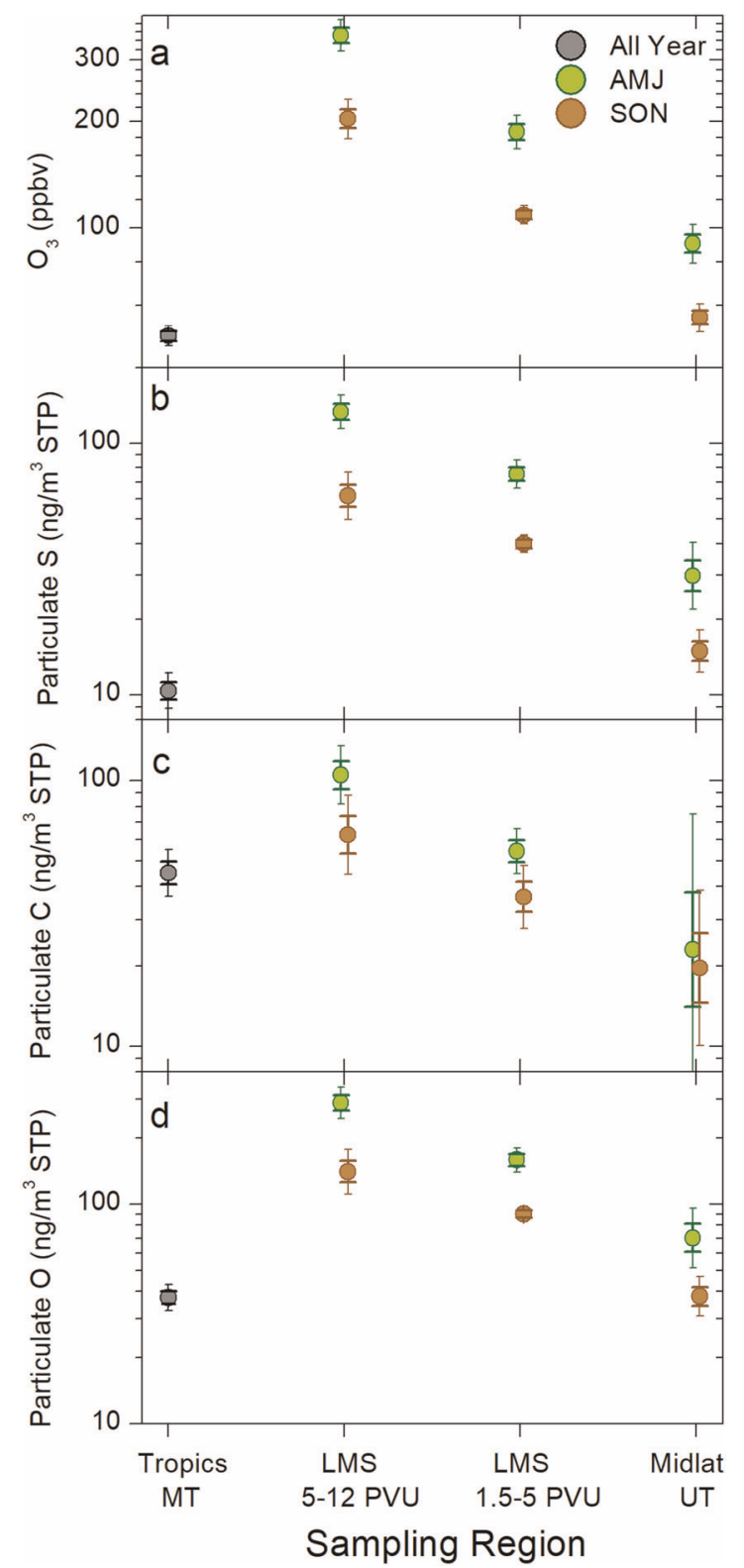

Fig. 4 Concentrations along the Brewer-Dobson circulation. Spring (AMJ) and fall (SON) geometrical mean concentrations in the $\mathrm{NH}$ midlatitude upper troposphere (UT) and two potential vorticity intervals of the lowermost stratosphere (LMS), and annual geometrical means of the tropical middle troposphere (MT) for a ozone, b particulate sulfur, c particulate carbon and $\mathbf{d}$ particulate oxygen. Thick and thin error bars show the geometrical standard error and the $95 \%$ confidence interval of the geometrical mean, respectively

overall a considerably longer duration. Photolytic loss, leading to carbon dioxide as the end product, ${ }^{33}$ is a reasonable explanation for this clear difference between the two kinds of aerosol. Despite the photolytic loss, electron microscopy reveals LMS particles containing a carbonaceous "framework". ${ }^{53}$ Here we find higher concentrations deep into the LMS, and enhanced carbon concentration in the season of strong downward transport to the LMS. Measurements with the PALMS (Particle Analysis by Laser Mass Spectrometry) show carbon fractions of the aerosol having only small vertical variations in a $2-8 \mathrm{~km}$ range above the tropopause, ${ }^{54}$ thus including our upper LMS layer up to several km above the top of the LMS (Fig. 1). Given the strong increase of the particulate sulfur concentration with altitude in the LMS and above the LMS, ${ }^{9,55}$ their results points to increasing concentration with altitude also for particulate carbon in line with our finding. The springtime transport of carbonaceous aerosol from overlying parts of the stratosphere into the LMS holds concentrations clearly exceeding those of the tropical MT. This indicates a direct-injected deep reservoir from wildfires, which however likely is subjected to strong photochemical loss, and/or that formation of carbonaceous aerosol takes place in the stratosphere during years of transport in the upper branch of the Brower-Dobson circulation. The latter explanation is supported by our evidence on the composition of the carbonaceous fraction of the stratospheric aerosol, which is found to be oxygen-poor compared with the tropospheric aerosol.

The composition and formation of the stratospheric aerosol is more complex than generally assumed. Besides the commonly recognized sulfurous aerosol, we find clear indications for the formation of a considerable fraction of organic aerosol. This increases the stratospheric aerosol load and its climate impact. It should be noted that highly acidic conditions are known to promote brown carbon $(\mathrm{BrC})$ formation, ${ }^{56}$ characterized by strong, wavelength-dependent absorption of visible light that could affect climate model predictions and interpretations of data from satellites. Future studies are needed to understand the composition and the sources of the carbonaceous fraction, the resulting optical properties of the stratospheric aerosol and its climate impact.

\section{METHODS}

We present results based on measurements from the IAGOS-CARIBIC observatory (In-service Aircraft for a Global Observing System - Civil Aircraft for Regular Investigation of the atmosphere Based on an Instrument Container) where measurements of a large number of trace gases, aerosol particle properties like size distributions and composition are conducted during monthly sets of usually four intercontinental flights. ${ }^{38}$ The measurements are undertaken from a specially modified Lufthansa Airbus A340-600 in the altitude range 9-12 km during flights between Germany and South-east Asia, India, Southern Africa, South America or North America. Here the focus is on the aerosol chemical information obtained by post-flight analysis of collected aerosol samples. The aerosol sampler contains 14 sampling channels for sequential aerosol collection along the flight routes, usually with a sampling time of $100 \mathrm{~min}$ per sample. It is based on impaction of particles onto thin $(0.2 \mu \mathrm{m})$ polyimide films (Proline-10 from Moxtek Inc.). The sampler was thoroughly calibrated, having the collection efficiency $97 \% \pm 4 \%$ and a lower cut-off aerodynamic diameter of $0.08 \mu \mathrm{m} .{ }^{57} \mathrm{~A}$ cyclone separator is used to define the upper size limit to $2 \mu \mathrm{m}$ with the penetration $100 \% \pm 3 \%$ for particles smaller than $1 \mu \mathrm{m}$. The samples are analyzed by two accelerator-based methods, PIXE (Particle-Induced X-ray Emission) and PESA (Particle Elastic Scattering Analysis), ${ }^{58}$ to obtain the concentration of a large number of chemical elements. These analytical methods are insensitive to the chemical environment of the atoms, implying that the total concentration of each element is obtained. This study deals with three main aerosol particle components: carbon $(C)$ and oxygen $(O)$ analyzed by PESA, and sulfur (S) analyzed by PIXE. The analyses are undertaken in high vacuum at room temperature which, compared to the atmospheric concentrations, leads to losses of volatile organic aerosol constituents. ${ }^{59,60}$ Recent measurements find considerable quantities of ammonium nitrate in the Asian summer monsoon anticyclone. ${ }^{61,62}$ If present in our samples, that compound most likely will be lost to the gas phase in the IAGOS-CARIBIC sampling line because of the elevated temperature $\left(30^{\circ} \mathrm{C}\right)$ compared with atmospheric conditions at $10 \mathrm{~km}$ altitude and the resulting dry conditions $(<0.1 \%$ relative humidity). The PIXE/PESA analyses have been compared with integrated particle size distributions from the IAGOS-CARIBIC optical particle size spectrometer ${ }^{60}$ with positive outcomes. The uncertainty in the elemental analyses are estimated to be $10 \%$, and the combined sampling and analytical uncertainties are $12 \% .^{60}$

In this study two layers in the LMS are investigated: the lowest layer range from the dynamical tropopause, defined here at $1.5 \mathrm{PVU}$, to $5 \mathrm{PVU}$, and the upper layer spans 5-12 PVU. Potential vorticity (PV) values are obtained from ECMWF analyses on model levels by bilinear interpolation in the time and space to the location of the IAGOS-CARIBIC aircraft. All LMS samples used in this study were taken in the latitude range $30-65^{\circ} \mathrm{N}$. 
Samples taken in the extratropical UT in the same latitude range were also used in this study. Data from the middle troposphere (MT, 9-12 km) in the tropics (latitude range $18^{\circ} \mathrm{S}-18^{\circ} \mathrm{N}$ ) are also part of this investigation. Some samples contain aerosol from more than one of these atmospheric parts. In order to reduce influence from cross-talk between the groups an initial screening was undertaken. Samples in the UT are required to be, besides having an average PV of less than $1.5 \mathrm{PVU}$, sampled less than $20 \%$ of the time in PV > 1.5 PVU and less than 3\% in PV > 3.5 PVU. Due to the strong, close to linear gradients in concentration against PV in the $\mathrm{LMS}^{9}$ somewhat leaner requirements were used to screen the LMS data, besides being on average within the PV boundaries, at least $60 \%$ of the sampling time should be in the LMS. The samples used in this study were taken in the time period 2005-2014. In this period the conditions in the LMS varied due to influence from volcanism..$^{8,17}$ To avoid effects of strong variability in the data set, only periods of relatively weak volcanic impact were used. The eruptions of Kasatochi (Aug. 2008), Redoubt (Mar.-Apr. 2009) and Sarychev (Jun. 2009) led to exclusion of data from Aug. 2008 until a break in IAGOSCARIBIC measurements that started in Oct. 2009 and lasted until Jun. 2010. The next eruptions to cause unusually high aerosol concentrations in the LMS were those of Grimsvötn (May 2011) and Nabro (Jun. 2011), leading to exclusion of data from Jun. 2011 until Jun. 2012. In addition, the eruption of Rabaul (Oct. 2006) induced very high concentrations for the season in Dec. 2006. ${ }^{10}$ Data from that month was not used either. After eliminating data strongly affected by volcanism the data set comprises 350 samples. The number of samples are 120 for the lower and 101 for the upper LMS layer. Due to the strong stratospheric influence on the extratropical UT, ${ }^{11}$ periods strongly impacted by volcanism were removed in the same way as described above for the LMS data. The extratropical UT data set comprises 60 samples. Because of the weak stratospheric influence on the tropical MT all data available were used, except three samples that were measured directly in recently uplifted volcanic cloud from an eruption of Nyamurgira in Nov. 2011. ${ }^{60}$ The number of tropical samples used in this study is 69.

The frequency of detection varied among the chemical elements studied. For sulfur and oxygen, we always obtained detection, i.e., $100 \%$ detection frequency. Due to strong influence from the carbon-rich sampling substrate (polyimide) the detection frequency of carbon is lower, ${ }^{58}$ being, for the tropical MT, the NH extratropical UT, LMS 1.5-5 PVU and LMS 5-12 PVU, 74\%, 63\%, 85, and 93\%. The concentrations of various groups were described by the geometrical mean and standard deviation. From these parameters and the number of samples, standard error and double-sided $95 \%$ confidence intervals were computed. This was straightforward for oxygen and sulfur. For carbon a log-normal distribution was fitted to the fraction of the data that was detected, while samples without detection were present in the fitting procedure as blanks below the lowest concentration of the distribution. Ratios between two elements is based on the geometrical averages of the elements and their covariance. Each geometrical mean given here is based on at least eight detections, with the additional constraint of detection in at least $50 \%$ of the samples. To obtain high statistical significance in monthly means, a 3-month sliding averaging technique was used..$^{11}$ All particle data in this study are provided for STP conditions (standard pressure $(1013.25 \mathrm{hPa})$ and temperature $(273.15 \mathrm{~K}))$.

The samples of the LMS are taken in a strong concentration gradient related to $\mathrm{PV} .{ }^{9}$ When studying seasonal variation of LMS data a method to obtain the same average PV among the different month was used, to avoid bias from seasonal variability in PV. Data points with the lowest or highest PV are eliminated depending on whether the average PV should increase or decrease to obtain the average. The procedure resulted in average PVs of $3.54 \pm 0.005 \mathrm{PVU}$ and $6.32 \pm 0.004 \mathrm{PVU}$ of the lower and higher LMS layer, where the uncertainties indicate the respective seasonal variation after the elimination procedure in the form of standard deviations.

The ozone concentrations presented are obtained from a fast chemiluminescence instrument and an accurate, dual-beam UV-photometer aboard the IAGOS-CARIBIC observatory. The estimated accuracy is $2 \%$ for $10 \mathrm{~Hz}$ measurements. ${ }^{38,63}$

\section{DATA AVAILABILITY}

The data used in this study are available from the corresponding author upon reasonable request.

Received: 4 July 2019; Accepted: 17 October 2019; Published online: 06 November 2019

\section{REFERENCES}

1. Fyfe, J. C., Gillett, N. P. \& Zwiers, F. W. Overestimated global warming over the past 20 years. Nat. Clim. Change 3, 767-769 (2013).

2. Fyfe, J. C. et al. Making sense of the early-2000s warming slowdown. Nat. Clim. Change 6, 224-228 (2016).

3. Medhaug, I., Stolpe, M. B., Fischer, E. M. \& Knutti, R. Reconciling controversies about the "global warming hiatus". Nature 545, 41-47 (2017).

4. Myhre, G. et al. In Climate Change 2013: The Physical Science Basis. Contribution of Working Group I to the Fifth Assessment Report of the Intergovernmental Panel on Climate Change. Stocker T.F., D. Qin, G.-K. Plattner, M. Tignor, S.K. Allen, J. Boschung, A Nauels, Y. Xia, V. Bex \& P.M. Midgley (eds), (Cambridge University Press, Cambridge, United Kingdom and New York, NY, USA, 2013).

5. Santer, B. D. et al. Volcanic contribution to decadal changes in tropospheric temperature. Nat. Geosci. 7, 185-189 (2014).

6. Vernier, J. P. et al. Tropical stratospheric aerosol layer from CALIPSO lidar observations. J. Geophys. Res. 114, https://doi.org/10.1029/2009JD011946 (2009).

7. Solomon, S. et al. The persistently variable "background" stratospheric aerosol layer and global climate change. Science 333, 866-870 (2011).

8. Andersson, S. M. et al. Significant radiative impact of volcanic aerosol in the lowermost stratosphere. Nat. Commun. 6, 7692 (2015).

9. Martinsson, B. G. et al. Characteristics and origin of lowermost stratospheric aerosol at northern midlatitudes under volcanically quiescent conditions based on CARIBIC observations. J. Geophys. Res. 110, D12201 (2005).

10. Friberg, J. et al. Sources of increase in lowermost stratospheric sulphurous and carbonaceous aerosol background concentrations during 1999-2008 derived from CARIBIC flights. Tellus B 66, 23428 (2014).

11. Martinsson, B. G. et al. Particulate sulfur in the upper troposphere and lowermost stratosphere - sources and climate forcing. Atmos. Chem. Phys. 17, 10937-10953 (2017).

12. Bönisch, H., Engel, A., Curtius, J., Birner, Th \& Hoor, P. Quantifying transport into the lowermost stratosphere using simultaneous in-situ measurements of $\mathrm{SF}_{6}$ and $\mathrm{CO}_{2}$. Atmos. Chem. Phys. 9, 5905-5919 (2009).

13. Gettelman, A., Kinnison, D. E., Dunkerton, T. J. \& Brasseur, G. P. Impact of monsoon circulations on the upper troposphere and lower stratosphere. J. Geophys. Res. 109, D22101 (2004).

14. Randel, W. J. \& Park, M. Deep convective influence on the Asian summer monsoon anticyclone and associated tracer variability observed with the Atmospheric Infrared Sounder (AIRS). J. Geophys. Res. 111, D12314 (2006).

15. Vernier, J.-P., Thomason, L. W. \& Kar, J. CALIPSO detection of an Asian tropopause aerosol layer. Geophys. Res. Lett. 38, L07804 (2011).

16. $\mathrm{Yu}, \mathrm{P}$. et al. Efficient transport of tropospheric aerosol into the stratosphere via the Asian summer monsoon anticyclone. PNAS 114, 6972-6977 (2017).

17. Friberg, J., Martinsson, B. G., Andersson, S. M. \& Sandvik, O. S. Volcanic impact on the climate - the stratospheric aerosol load in the period 2006 - 2015. Atmos. Chem. Phys. 18, 11149-11169 (2018).

18. Murphy, D. M., Thomson, D. S. \& Mahoney, M. J. In situ measurements of organics, meteoritic material, mercury, and other elements in aerosols at 5 to 19 kilometers, Science 282, https://doi.org/10.1126/science.282.5394.1664 (1998).

19. Deshler, T. A review of global stratospheric aerosol: Measurements, importance, life cycle, and local stratospheric aerosol. Atmos. Res. 90, 223-232 (2008).

20. Martinsson, B. G. et al. Influence of the 2008 Kasatochi volcanic eruption on sulfurous and carbonaceous aerosol constituents in the lower stratosphere. Geophys. Res. Lett. 36, L12813 (2009).

21. Andersson, S. M. et al. Composition and evolution of volcanic aerosol from eruptions of Kasatochi, Sarychev and Eyjafjallajökull in 2008 - 2010 based on CARIBIC observations. Atmos. Chem. Phys. 13, 1781-1796 (2013).

22. Schwarz, J. P. et al. Global-scale black carbon profiles observed in the remote atmosphere and compared to models. Geophys. Res. Lett. 37, https://doi.org/ 10.1029/2010GL044372 (2010).

23. Ditas, J. et al. Strong impact of wildfires on the abundance and ageing of black carbon in the lowermost stratosphere. PNAS 115, E11595-E11603 (2018).

24. Fromm, M. et al. The untold story of pyrocumulonimbus. Bull. Am. Meteorol. Soc. 91, 1193-1209 (2010).

25. Crutzen, P. J. The possible importance of CSO for the sulfate layer of the stratosphere. Geophys. Res. Lett. 3, 73-76 (1976).

26. Brühl, C., Lelieveld, J., Crutzen, P. J. \& Tost, H. The role of carbonyl sulphide as a source of stratospheric sulphate aerosol and its impact on climate. Atmos. Chem. Phys. 12, 1239-1253 (2012).

27. Noziere, B. \& Esteve, W. Organic reactions increasing the absorption index of atmospheric sulfuric acid aerosols. Geophys. Res. Lett. 32, https://doi.org/10.1029/ 2004GL021942 (2005).

28. Van Wyngarden, A. L. et al. Complex chemical composition of colored surface films formed from reactions propanal in sulfuric acid at upper troposphere/lower stratosphere aerosol acidities. Atmos. Chem. Phys. 15, 4225-4239 (2015). 
29. Malecha, K. T., Cai, Z. \& Nizkorodov, S. A. Photodegradation of secondary organic aerosol material quantified with a quartz crystal microbalance. Environ. Sci. Technol. Lett. 5, 366-371 (2018).

30. Hallquist, $M$. et al. The formation, properties and impact of secondary organic aerosol: current and emerging issues. Atmos. Chem. Phys. 9, 5155-5236 (2009).

31. Shrivastava, M. et al. Recent advances in understanding secondaey organic aerosol: Implications for global climate forcing. Rev. Geophys. 55, 509-559 (2017).

32. Aiken, $\mathrm{A}$. C. et al. $\mathrm{O} / \mathrm{C}$ and $\mathrm{OM} / \mathrm{OC}$ ratios of primary, secondary, and ambient organic aerosols with high-resolution time-of-flight aerosol mass spectrometry. Environ. Sci. Technol. 42, 4478-4485 (2008).

33. Jimenez, J. L. et al. Evolution of organic aerosol in the atmosphere. Science 326, 1525-1529 (2009).

34. Jokinen, T. et al. Production of extremely low volatile organic compounds from biogenic emissions: measured yields and atmospheric implications. PNAS 112, 7123-7128 (2015).

35. Schobesberger, S. et al. Molecular understanding of atmospheric particle formation from sulfuric acid and large oxidized organic molecules. PNAS 110, 17223-17228 (2013)

36. Molina, M. J., Ivanov, A. V., Trakhtenberg, S. \& Molina, L. T. Atmospheric evolution of organic aerosol. Geophys. Res. Lett. 31, L22104 (2004).

37. Sareen, N., Moussa, S. G. \& McNeill, V. F. Photochemical aging of light-absorbing secondary organic aerosol material. J. Phys. Chem. A 117, 2987-2996 (2013).

38. Brenninkmeijer, C. A. M. et al. Civil aircraft for the regular investigation of the atmosphere based on an instrumented container: the new CARIBIC system. Atmos. Chem. Phys. 7, 4953-4976 (2007).

39. Gettelman, A. et al. The extratropical upper troposphere and lower stratosphere. Rev. Geophys. 49, https://doi.org/10.1029/2011RG000355 (2011).

40. Appenzeller, C., Holton, J. R. \& Rosenlof, K. H. Seasonal variation of mass transport across the tropopause. J. Geophys. Res. 101, 15071-15078 (1996).

41. Skerlak, B., Sprenger, M. \& Wernli, H. A global climatology of stratospheretroposphere exchange using the ERA-Interim data set from 1979 to 2011. Atmos. Chem. Phys. 14, 913-937 (2014).

42. Peterson, D. A. et al. Wildfire-driven thunderstorms cause a volcano-like stratospheric injection of smoke. Npj Clim. Atmos. Sci. 1, 30 (2018)

43. Vernier, J.-P. et al. Increase un upper tropospheric and lower stratospheric aerosol levels and its potential connection with Asian pollution. J. Geophys. Res. Atmos. 120, https://doi.org/10.1002/2014JD022372 (2015).

44. Guenther, A. B. et al. The model of emissions of gases and aerosols from nature version 2.1 (MEGAN2.1): an extended and updated framework for modeling biogenic emissions. Geosci. Model Dev. 5, 1471-1492 (2012).

45. Van der Werf, G. R. et al. Global fire emissions estimates during 1997-2016. Earth Syst. Sci. Data 9, 697-720 (2017).

46. Friberg, J. et al. Influence of volcanic eruptions on midlatitude upper tropospheric aerosol and consequences for cirrus clouds. Earth Space Sci. 2, https://doi.org/ 10.1002/2015EA000110 (2015).

47. Gondwe, M., Krol, M., Gieskes, W., Klaassen, W. \& de Baar, H. The contribution of ocean-leaving DMS to the global atmospheric burdens of DMS, $\mathrm{MSA}, \mathrm{SO}_{2}$, and NSS SO 4 . Glob. Biogeochem. Cycles 17, 1056 (2003).

48. Sheng, J.-X. et al. Global atmospheric sulfur budget under volcanically quiescent conditions: aerosol-chemistry-climate model predictions and validation. J. Geophys. Res. Atmos. 120, 256-276 (2015).

49. Khaykin, S. M. et al. Stratospheric smoke with unprecedentedly high backscatter observed by lidars above southern France. Geophys. Res. Lett. 45, 1639-1646 (2018).

50. Hodzic, A. et al. Organic photolysis reactions in tropospheric aerosols: effects on secondary organic aerosol formation and lifetime. Atmos. Chem. Phys. 15, 9253-9269 (2015).

51. Garofalo, L. A. et al. Emission and evolution of submicron organic aerosol in smoke from wild fires in the western United States. ACS Space Chem. 3, 1237-1247 (2019).

52. $\mathrm{Yu}, \mathrm{P}$. et al. Black carbon lofts wildfire smoke high into the stratosphere to form a persistent plume. Science 365, 587-590 (2019).

53. Nguyen, H. N. et al. Chemical composition and morphology of individual aerosol particles from a CARIBIC fight at $10 \mathrm{~km}$ altitude between $50^{\circ} \mathrm{N}$ and $30^{\circ} \mathrm{S}$. J. Geophys. Res. 113, D23209 (2008).

54. Murphy, D. M., Cziczo, D. J., Hudson, P. K. \& Thomson, D. S. Carbonaceous material in aerosol particles in the lower stratosphere and tropopause region. J. Geophys. Res. 112, D04203 (2007).

55. Weisenstein, D. K. et al. A two-dimensional model of sulfur species and aerosols. J. Geophys. Res. 102, 13019-13035 (1997).
56. Laskin, A., Laskin, J. \& Nizkorodov, S. A. Chemistry of atmospheric brown carbon. Chem. Rev. 115, 4335-4382 (2015).

57. Nguyen, H. N., Gudmundsson, A. \& Martinsson, B. G. Design and calibration of a multi-channel aerosol sampler for studies of the tropopause region from the CARIBIC platform. Aerosol Sci. Technol. 40, 649-655 (2006).

58. Nguyen, H. N. \& Martinsson, B. G. Analysis of C, N and O in aerosol collected on an organic backing using internal blank measurements and variable beam size. Nucl. Instr. Meth. B 264, 96-102 (2007).

59. Martinsson, B. G. An external beam PIXE/PESA setup for characterization of fine aerosols. Nucl. Instr. Meth. B22, 356-36 (1987).

60. Martinsson, B. G. et al. Comparison between CARIBIC aerosol samples analysed by accelerator-based methods and optical particle counter measurements. Atmos. Meas. Tech. 7, 2581-2596 (2014).

61. Vernier, J.-P. et al. BATAL - The balloon measurement campaigns of the Asian tropopause aerosol layer. Bull. Am. Meteorol. Soc. 99, 955-973 (2018).

62. Höpfner, M. et al. Ammonium nitrate particles formed in upper troposphere from ground ammonia sources during Asian monsoons. Nat. Geosci. 12, 608-612 (2019).

63. Zahn, A. et al. A fast and precise chemiluminescence ozone detector for eddy flux and airborne application. Atmos. Meas. Tech. 5, 363-375 (2012).

\section{ACKNOWLEDGEMENTS}

Thanks to all the members of the IAGOS-CARIBIC project, Lufthansa and Lufthansa Technik for enabling the IAGOS-CARIBIC observatory. Financial support from the Swedish National Space Board (contract 130/15) and the Swedish Research Council for Environment, Agricultural Sciences and Spatial Planning (contracts 942-2015-995 and 2018-00973) is gratefully acknowledged. Open access funding provided by Lund University.

\section{AUTHOR CONTRIBUTIONS}

B.G.M. designed the study, undertook the data analyses and wrote the paper. B.G.M., J.F. and O.S.S. performed the ion beam analytical tasks, P.F.J.v.V. provided meteorological analyses M.H. is organizer of the IAGOS-CARIBIC aerosol module and A.Z. is responsible for the ozone measurements and the coordinator of IAGOS-CARIBIC. All co-authors provided input in discussion and to the writing of the manuscript.

\section{COMPETING INTERESTS}

The authors declare no competing interests.

\section{ADDITIONAL INFORMATION}

Correspondence and requests for materials should be addressed to B.G.M.

Reprints and permission information is available at http://www.nature.com/ reprints

Publisher's note Springer Nature remains neutral with regard to jurisdictional claims in published maps and institutional affiliations.

Open Access This article is licensed under a Creative Commons Attribution 4.0 International License, which permits use, sharing, adaptation, distribution and reproduction in any medium or format, as long as you give appropriate credit to the original author(s) and the source, provide a link to the Creative Commons license, and indicate if changes were made. The images or other third party material in this article are included in the article's Creative Commons license, unless indicated otherwise in a credit line to the material. If material is not included in the article's Creative Commons license and your intended use is not permitted by statutory regulation or exceeds the permitted use, you will need to obtain permission directly from the copyright holder. To view a copy of this license, visit http://creativecommons. org/licenses/by/4.0\%.

(c) The Author(s) 2019 